\title{
¿Existe la materia? Un estudio en torno a la formación del concepto en la filosofía y en la ciencia, $1973^{*}$
}

\author{
Hans-Georg Gadamer
}

[201] La ciencia de los tiempos modernos desde siempre ha sabido sus orígenes griegos, y se ha remitido a la autoridad del pensamiento griego. Basta pensar, tan sólo, en las obras originales de Copérnico y Kepler o en Newton o en los grandes investigadores de los siglos XIX y xx; como representante de ellos mencionaremos únicamente a Helmholtz. Ciertamente, entre los pioneros de la ciencia moderna como también entre sus intérpretes filosóficos, tanto en Kant y el neokantismo como con Ernst Mach o Max Planck, fue sobre todo Platón, cuya imaginación filosófica se consideraba -hasta nuestros días- como una anticipación de los conocimientos más recientes. Aristóteles, por el contrario, desde los días de Galileo, siempre estuvo bajo sospecha de ser un dogmático y el nuevo interés por Aristóteles, que encontramos en Schelling y Hegel, los defensores de una física "especulativa", no lo ayudó, precisamente, a conseguir el reconocimiento en la época moderna -y esto a pesar de que una gran parte de los conceptos con los cuales trabajan tanto la filosofía como la ciencia, son indudablemente de origen aristotélico-. "Aristóteles fue un farmacéutico", esta sentencia ilustre de Hermann Cohen, quien reparó en Aristóteles, a diferencia de Platón, solamente una clasificación secundaria en acción es reconocida todavía en la actualidad por vastos círculos de investigadores de las ciencias naturales, sobre todo, con miras a hacer dependiente la matemática de la naturaleza y su crítica a Platón que parece puntillosa y construida sobre malos entendidos.

Pues bien, entretanto, se efectuó un cambio en la investigación filosófica que empieza a revisar un esquematismo dogmático en la comprensión de Aristóteles. En parte, a través del análisis filológico, en parte, por la nueva

* Hans-Georg Gadamer, "Gibt es die Materie? Eine Studie zur Begriffsbildung in Philosophie und Wissenschaft", en Gesammelte Werke 6. Griechische Pilosophie II. Tübingen, J. C. B. Mohr (Paul Siebeck), 1985/1999, pp. 201-217. 
interpretación filosófica se llegó a descubrir que Aristóteles fue y sigue siendo mucho más platónico de lo que se había pensado. Sobre todo, la comparación de Aristóteles, el realista, y de Platón, el idealista, motivada por la crítica neotomista del idealismo moderno se desmoronó por completo. Lo común que mantiene a la filosofía de Atenas, "la dialéctica" socrática, constituye el hilo conductor de toda profundización seria en Aristóteles.

[202] Sin embargo, la idea que se tiene de Aristóteles sigue siendo muy controvertida. Si uno estudia, por ejemplo, la obra erudita y extremamente circunspecta, Hyle de H. Happ, ${ }^{1}$ se nota que aún persisten los viejos antagonismos, aunque en nuevas formas. ¿Será la hyle un principio meramente pasivo, como Stenzel, Wieland y Düring parecen suponer o corresponde a este "principio del ser" también algo de activo? Aproximadamente así pregunta Happ. Permítaseme tomar esa sentencia como punto de referencia. Ésta parece apropiada para discutir, en el ejemplo dado del concepto de hyle, algo en torno a la formación del concepto en la ciencia y la filosofía.

Como es sabido, hyle se encuentra en el contexto sistemático de la doctrina de las cuatro causas, las "aitiai" o "archai" de lo existente por naturaleza, e igualmente, claro está, que con estas maneras del ser fundamental, estas "causas", no se trata de "cosas", ni siquiera de algo existente, sino de las concepciones básicas desde las cuales se habla del "ser" de tal ente. La concepción es lo que se está viendo cuando uno hace una declaración acerca de algo. De esta manera se diferencia, como se sabe, la afirmación acerca del ente en Aristóteles, en la multiplicidad de las categorías y que todas ellas incluyen la concepción conductora de lo que es. Pero las concepciones son también las cuatro aitiai de la Física, el qué es mismo y aquello de lo que está hecho, el a través de qué está hecho y el para qué está hecho. Como modos de la causa también se pueden comprender como modos de caracterizar el esquema de respuesta a la pregunta

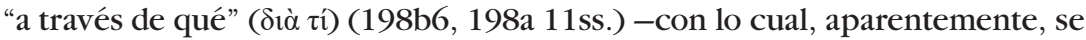
trata de un concepto muy formal del "a través de qué"-. También el "de qué está hecho" de la hyle permite remitir al "a través de qué está hecho", como Aristóteles dice. Un concepto tan formalmente extenso de "causa" podría ser formulado por la siguiente pregunta: ¿qué existe realmente cuando uno habla del ser de tal ente? Pues es evidente que estas concepciones de lo "existente" saltan a la vista primariamente en el área de la techne. Ahí se destacan, visiblemente, las cuatro concepciones para hablar de algo prístino, a lo cual, el respectivo existente puede ser "reducido" (ảvó $\gamma \varepsilon \tau \alpha$ ): el material, el aspecto (o sea la forma), el impulso del movimiento o el origen de la acción y el móvil de la acción o la finalidad. A nadie se le ocurriría, en esta explicación de lo

${ }^{1}$ Heinz Happ, Hyle. Studien zum aristotelischen Materiebegriff. Nueva York/ Berlín, 1971. 
perteneciente al hacer, atribuirle al material un "impulso", un "ser activo": idoneidad ciertamente - el artesano que tiene en mente la finalidad y la forma planeada, también incluiría esto en sus concepciones cuando escoge y consigue el material idóneo, y él deberá tomar en consideración su propia fuerza de trabajo y la respectiva distribución del tiempo (la causa del impulso)-.

Pues bien, evidentemente, lo principal de la formación del concepto aristotélico es que las concepciones conceptuales que se diferencian palpablemente unas de las otras [203] son, también, indispensables, aun sin contrastarse, para entender la physis. A ello sirve, en especial, el razonamiento "histórico" en la Física A y, más aún, en la Metafísica A donde Aristóteles busca comprobar, en lo relativo a los filósofos antiguos griegos, que su propio análisis de las cuatro causas puso de relieve plenamente los conocimientos de causa y los impulsos provenientes de ellos. El muy criticado esquema de esta síntesis "doxográfica", en verdad es, si uno no pierde de vista su intención teórica, de suprema diferenciación "histórica" y, particularmente, el problema de la "materia", y la acuñación aristotélica del concepto de hyle, sobresalen claramente como concepción interrogativa de las tradiciones históricas a las que Aristóteles los

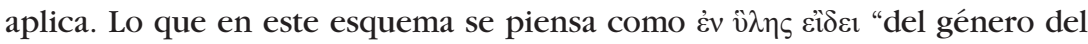
material”, evidentemente no se concibió partiendo de la techne, como es el caso del concepto aristotélico. Pues es "el mundo" en el cambio de sus manifestaciones que plantea a estos pensadores la pregunta por lo permanente en

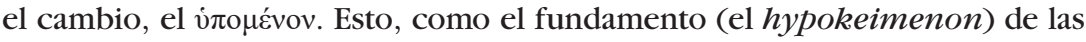
jurisdicciones cambiantes ( $\pi \dot{\alpha} \theta \eta)$, debería ser el verdadero ser de la naturaleza. Cuando Aristóteles caracteriza este fundamento como hyle, no sólo hace notar la esfera de la techne, sino apunta, críticamente, al ocultamiento radical de lo propiamente permanente en la naturaleza que se encuentra en este tipo de preguntas (como por ejemplo): ¿cuál es la base permanente? Se oculta aquello que en el área de la techne se presenta visiblemente como eidos, la morphe de la cosa a producir. Lo que permite a la naturaleza ser rigurosamente naturaleza no es que un portador indefinido admita características cambiantes a discreción, como, por ejemplo, que Sócrates llegara, además, a ser bello o músico (983b 14). Lo primero no se le dio en lo absoluto; y lo segundo le resultó no muy bien cuando, estando en prisión, puso las fábulas de Esopo en versos. - La naturaleza no es, en efecto, el desarrollo de tales discrecionalidades. Aunque los antiguos atribuyeron el momento del movimiento a su materia prima o a uno de los contrarios en los cuales se mueve el equilibrio de la naturaleza, no habrá ninguna mejoría. El ocultamiento del eidos y del telos impide pensar la naturaleza como naturaleza. Éste es el tenor crítico de la Metafísica A 3-.

De esa manera, la extrapolación con base en la techne, a través de la cual Aristóteles enseña a pensar el ser de la naturaleza, prestó sus buenos servicios. Pero ésta tuvo, para la comprensión de Aristóteles, consecuencias fatales. Ya 
los antiguos y, aún más, el aristotelismo del Renacimiento transmitido medieval y neoplatónicamente, entendieron la formación de conceptos teleológicos de Aristóteles como una teleología natural dogmática. Ya no comprendieron que la formación de conceptos aristotélicos, efectivamente, se inspiró en la techne, y que la analogía con la techne fijó las interrogantes, pero que Aristóteles mismo, a través de la doctrina de las cuatro causas, no quiso, de ninguna manera, introducir causalidades arcanas. Del acervo común de esta aplicación dinámico-teleológica de los conceptos aristotélicos también forma parte nuestro pro[204]blema de la masa "activa". Lo que esto quiere decir de ninguna manera se puede expresar con los conceptos aristotélicos. Significaría que la "materia", a su vez, quiere decir cómo este último concepto, apenas aceptado, sería visto como un ser existente al cual, sin embargo, le debiera corresponder, de nuevo, una causa de movimiento. No tan sólo que uno, a la inversa, podría hablar con el mismo derecho, de una causa de movimiento material, un eidos o un telos material o moviente. Ambas ideas son igualmente absurdas: las "causas" de la teoría aristotélica del ser de la naturaleza y del ser de lo existente tienen precisamente el sentido de distinguir la complejidad de las razones bajo las cuales existe el "ser". De hecho, todas y cada una de ellas pertenecen a la constitución de este ser, pero ellas mismas no son -como "fundamento del ser"- "lo existente" del carácter de "esto". Todo discurso de una materia "definida" que ciertamente aparece en un contexto descriptivo de Aristóteles, nombra "lo existente" al que, sin duda, corresponde su determinación (eidos), y no significa la "pura" hyle misma que, a su vez, está definida por la indeterminación. -Que no me vengan con la objeción de que esto es una interpretación aristotélica en extremo nominalista y, por eso, ahistórica. La aplicación de estos conceptos acertados para la Edad Media, tanto para Aristóteles como para Platón es, por el contrario, ahistórica y anacrónica. Ciertamente, las "causas" de Aristóteles "son" tan buenas como las "archai" de la doctrina de las ideas platónicas, a saber, no son exclusivamente aquello a partir de lo cual se conocen las cosas (o las ideas), sino de igual manera, de donde ellas "son", para hablar con la diferencia aristotélica. Pero ellas mismas no "son" lo existente, a saber, no son "por sí". Ni hyle ni eidos, que pueden denominarse

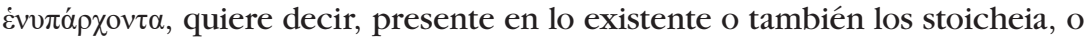
sea "los elementos", son "conceptos reales" del "todo" ( $\sigma u ́ v o \lambda o v)$ y este todo no es una unidad de cosas diferentes, por lo cual se podría preguntar por un dónde de su ser uno, como dice Aristóteles con toda la claridad (Met. H 6).

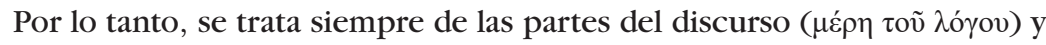
en eso se mantiene Aristóteles, como la nueva investigación ha constatado con razón, en la línea del planteamiento platónico de preguntas, el cual en el Fedón, se contrapone a todo conocimiento del mundo anterior. El Timeo - con todo su tono de relatos, esto es inequívoco- habla de la "chora", del principio que 
otorga un lugar que debe ser inferido del pensamiento para el ser del orden del ser ideal, por lo tanto, del puro "en qué" del ser. La pregunta de qué se trata de una pura extensionalidad o de una "verdadera" materia, no tiene sentido. Simplicio $^{2}$ explica muy bien por qué esta deducción pensante a un "en qué"

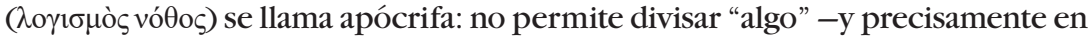
este sentido de la formación análoga [205] de conceptos, también Aristóteles habla de hyle-. Ciertamente, lo dice con una insistencia especial. Pues, para él, el punto de partida ya no es, como en el Timeo, la matemática celestial pitagórica y la armonía platónica de las ideas que apenas conduce a Platón a la metáfora del entendimiento "material", a través del cual entra la opacidad y la limitación de la pureza de la estructura del mundo matemático-ideal. Lo que es, es más bien como la realidad primera e incuestionable, el ser "natural" que siempre es las dos cosas, eidos y hyle, y como algo en movimiento nunca es la pureza "ideal" de la pura abstracción. En esto insistió Aristóteles. En el desarrollo de la pregunta básica de la "metafísica", él toma muy en serio que, tal vez, no exista otro verdadero ser que los entes visibles en movimiento, caracterizados por su automovimiento. Ellos son un todo del eidos y la hyle -la

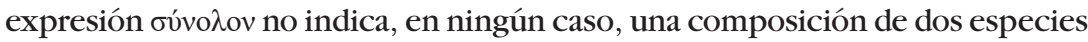
diferentes, sino, por el contrario, una unidad inseparable. Como expresión este giro se presenta, aparentemente, en un sentido muy cotidiano: "en total" (como, por ejemplo, en Platón). Aristóteles es el primero en usar la expresión como sustantivo y como un término "el todo" donde el eidos y la hyle son tan inseparables como en su famoso ejemplo de la chatedad [Stubsigkeit], donde el idioma mismo no separa el vocablo; ya que "chato" [Stubs] sólo se le puede usar en el compuesto nariz chata [Stubsnase]. ${ }^{3}$

Aristóteles no tan sólo acuñó esta expresión "synholon" y otorgó a la expresión "hyle" el carácter de concepto, sino parece haber hecho todo un esfuerzo para mantener alejadas ciertas ideas materio-corporales. Cuando él usa hyle fuera del contexto lingüístico "natural" de la artesanía y la introduce como un vocablo filosófico conceptual, él subraya, conscientemente, el carácter funcional de este concepto. Él introduce, ${ }^{4}$ primeramente, el concepto del "de qué" ( $\grave{\xi}$ oũ) enunciando, como ejemplos, relaciones tan formales como las premisas del final o las partes del conjunto -al lado de los "ejemplos técnicos" del material y de su moldeo técnico (An. Post. B11; Fís. B3). Y cuando reflexiona, expresamente, sobre el carácter funcional de los conceptos de hyle y de eidos para el ser de lo existente, como en Met. H, no deja ninguna duda de que aquí

${ }^{2}$ Simplicio, en el Aristotelis Physicorum Commentaria. Berlín, Berolini, 1882, $229,3$.

${ }^{3}$ N. T.: Stubsigkeit: chatedad. Stubsnase: en lengua alemana es una palabra compuesta y usada, exclusivamente, para referirse a la nariz chata.

${ }^{4}$ Aristóteles, Física, B3, 194 b 24. 
no se trata de una unión de cosas diferentes-. Pero esto no le ayudó en nada. Un investigador de la talla de Stenzel -y otros (Werner Jaeger, I. Düring, yo mismo y W. Wieland) lo seguimos en esto-sí tomó en serio el texto de Met. H y reconoció la indefinición de lo genéricamente universal como el verdadero sentido de hyle. Pero en contra del dogmatismo unánime de los intérpretes antiguos y la ingenuidad conceptual filosófica no se pudo hacer nada. Si la materia de por sí no debería ser material, entonces sí debería ser, por lo menos, un "principio [206] del ser", el cual interviene de "una manera sumamente activa en el proceso del devenir" (Happ, p. 763). Uno lo lee con asombro. ¿A ojos vistas, existe -contrario a las afirmaciones generales en el libro Met. A- otra "causa del moverse", además de la descrita por Aristóteles, a saber "en" la hyle? Para ello, uno se remite, sobre todo, a un pasaje, Fís. A 9 (192a 22 ss.), donde dice que la materia "requiere" el eidos como lo femenino a lo masculino. De hecho, Aristóteles tiene más que suficientes motivos para limitar la analogía con la techne, de tal manera que no es posible el moldeamiento discrecional, como en el caso de la elaboración "técnica" del material lo que asciende a la "base", al "sustrato" del ser natural. De una bellota nace, exclusivamente, un roble y es el hombre quien crea al hombre. Pero justo esto buscó Aristóteles

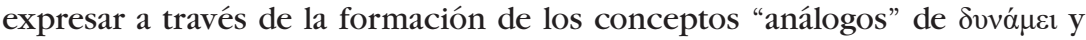

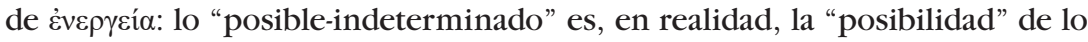
determinado. Para quien aquí interpreta un antropoformismo teleológico, Aristóteles en vano escribió el análisis agudo de Met. $\Theta$ donde él destaca el

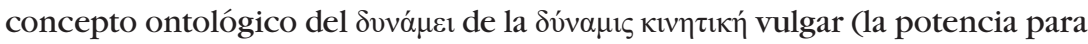
el mover y el ser movido) ciertamente importante en la doctrina del movimiento. Nos mantenemos en lo dicho: quien niega la autonomía y la "actividad" del principio material, cae en una interpretación monista de Aristóteles, donde, en efecto, los testimonios deben evidenciar, sin lugar a dudas, el dualismo de la materia y la forma.

No se me hace fácil de entender con qué derecho se aplican tales conceptos del sistema de la filosofía erudita, como el monismo y el dualismo a textos de la Antigüedad. Me parece incomprensible qué clase de "causalidad" debiera tener la materia en Aristóteles excepto de ser la causa última correspondiente

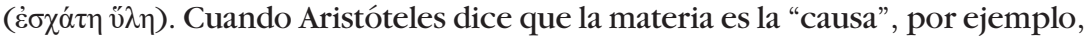
de malformaciones en la naturaleza o de la (¡no necesariamente deforme!) "individualidad" de los ejemplares de una "especie", no me imagino, en mi ingenuidad conceptual, la materia sino que, en este caso, siempre existe un ser determinado, por ejemplo, un hombre y su semen (o la "sangre menstrual"), un ente que por su eidos determinado se distingue unívocamente de los leones o de los insectos. También estoy dispuesto a imaginarme el huevo fecundado del que se desarrolla el embrión y, finalmente, el recién nacido. Pero se me dificulta concebir "a la materia" que quiere llegar a ser todo esto. 
Se me objetará airadamente que la materia es, en efecto, un principio del ser "independiente". Ciertamente, es un primado al que volvemos, teniendo en mente "el ser", pero no algo atrás de lo cual podemos ir. Esto es el "ser" del principio. Pero aun así no hay principios como las estrellas en el cielo que a Nicolai Hartmann le gustó tanto observarlas con su telescopio de Zeiss, ${ }^{5} \mathrm{o}$ como "fuerzas" independientes que constituyen una resultante. [207] Así se puede leer en el excelente trabajo de Nicolai Hartmann Sobre la teoría del

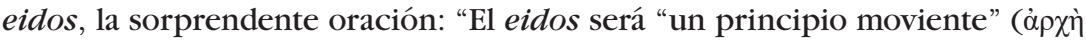
$\kappa \imath \eta \dot{\sigma \varepsilon}(\varsigma)$, y en este significado dinámico, se acerca, por lo menos, al propio sentido de un principio (i!)”. ${ }^{6}$ Aquí se aplican puros conceptos aristotélicos

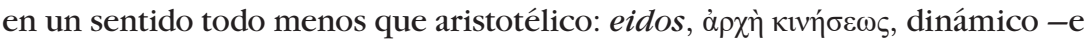
incluso "principio" ( $\alpha \rho \chi \eta ́)-$. Se objetará que nadie lo ve de esta manera. En efecto, sólo se trata del hecho de que se debe defender el dualismo de la forma y la materia en contra de una construcción de sistemas monistas al estilo de Plotino. Y como concordaremos en que no se debe interpretar a Aristóteles como neoplatónico-gnóstico, aunque nosotros nos expresemos de una manera muy funcionalista, en esencia siempre llegará a ser un "dualismo". Uno podrá remitirse, además, a numerosos pasajes, no tan sólo a aquel de la Física donde Aristóteles mismo le atribuye una actividad a la hyle. -Cuando Aristóteles quiere describir hechos empíricos, él, efectivamente, puede expresarse de la siguiente manera: que "depende de la hyle" y él conduce esta idea del "de qué" hasta los elementos, como quien dice, hasta el último sustrato-. Pero en tanto que los elementos, por su lado, están determinados de una manera muy contrastante está claro que no son un último indeterminado. Cuando uno los denomina "manifestaciones de la materia" - y luego denomina a "esta materia" la materia "primera" - ¿qué quiere decir esto? Todo ser que aparece en la naturaleza es "una manifestación de la materia", y Aristóteles tiene para dicha "manifestación” un buen vocablo griego, completamente platónico: ¡eidos! Algo similar podría decirse en lo relativo a la teoría de Aristóteles que es más escandalosa para la mentalidad moderna, según la cual existe un "último" eidos que es indivisible; y como la diferencia entre Calias y Sócrates no es ninguna diferencia en cuanto al "ser" y tampoco en cuanto al eidos, entonces estribaría en la hyle. La materia es, por lo tanto, el principio aristotélico de individuación. No quiero preguntar cómo corresponde esto al "alma" de Sócrates o, por lo menos, a su espíritu o si Aristóteles ya no pudo percibir el culto religioso a los muertos entre los griegos o si él permitió, a lo sumo, el panteísmo averroísta...

${ }^{5} \mathrm{~N}$. T.: Zeiss es una marca alemana de aparatos ópticos y fotográficos muy conocida y prestigiosa.

${ }^{6}$ Nicolai Hartmann, Escritos menores. Berlín, De Gruyter, vol. 2, 1957, pp. 129164, p. 141. 
¿Habrá Aristóteles, en realidad, preguntado de tal manera que se podría hablar de un principio de individuación en sus escritos? Él, en efecto, insistió con la mayor agudeza y con suma precisión que lo individual y su esencia ( $\tau i$ ทेv عĩval), a saber, la "sustancia primera" del "éste-aquí" y la "sustancia segunda" del "qué" no son dos cosas distintas, sino aspectos de lo mismo. ¿Lo mismo de qué? ¿Qué clase de aspectos?

Uno podrá sobrellevar discursos de principios que se materializan sólo a través de más que meras aseveraciones, si se trae a la memoria los fundamentos me[208] tódicos del filosofar platónico-aristotélico. Sólo así uno se ve en la posibilidad de dar un sentido claro también al discurso de la teleología natural, la cual, de hecho, domina el pensamiento aristotélico sobre el ser. Lo que de esto resulta está muy lejos de las ideas vulgares contra las cuales debió imponerse la nueva ciencia moderna a través de su crítica de las "causas finales". Se trata de tener muy presente el programa de una explicación teleológica del mundo que Platón pone en boca de Sócrates, en el Fedón (98a-f). Todas las preguntas que Sócrates en vano dirigió a Anaxágoras, a saber, por qué el mundo está en la condición actual que está, encuentran su horizonte inicial y final en la comprensión de él mismo, en su propia vida enfocada hacia lo correcto y lo bueno. Es, por lo tanto, una cierta medida de comprensión la que lo guía y lo conduce hacia la nueva salida y a refugiarse en los logoi. Los logoi son el área de la comprensión y del discurso donde se presenta, lingüísticamente, nuestra experiencia del mundo. Por lo tanto, Platón denomina a la filosofía de manera simple "dialéctica" y Aristóteles quien se guía por la misma norma de la

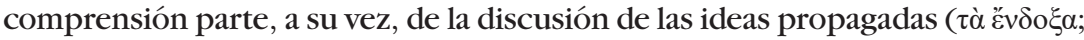
$\tau \grave{\alpha} \lambda \varepsilon \gamma o ́ \mu \varepsilon v \alpha)$-lo que él denomina "dialéctica"-. Su guía no es, por lo tanto, "la lengua", aunque muchas veces toma sus conceptos, a saber, sus medios de explicación, de la comprensión general del mundo, de los giros lingüísticos del discurso cotidiano. ${ }^{7}$ Sin embargo, lo que constituye el punto de partida y el objeto del pensamiento aristotélico no son estas estructuras del lenguaje como tales, sino las opiniones propagadas al hablar, la comprensión del mundo, en la cual nos movemos, preguntando y respondiendo, argumentando y contraargumentando. De esa manera se debe entender lo que es la naturaleza y cómo Sócrates quiere que se la entienda. Pero aquí se hace evidente que nosotros entendemos por naturaleza, no tan sólo el orden ideal sustentado por el cosmos de las ideas platónico-pitagóricas, como un modelo de construcción, descrito en el Timeo. En todo caso, el concepto platónico del eidos es, sin embargo, indispensable si se quiere entender cómo le hace la naturaleza para que sea

${ }^{7}$ Wolfgang Wieland hizo observaciones importantes en su hermoso libro Die aristotelische Physik acerca de la formación de los conceptos aristotélicos, pero no distinguió lo suficientemente claro entre las estructuras lingüísticas y las opiniones especializadas formuladas lingüísticamente. 
naturaleza. Por supuesto esto no es suficiente. Naturaleza -a diferencia de la techne- quiere decir que aquello que constituye las expresiones constantes del orden de las especies y la regularidad de los procesos de la naturaleza, es un único y gran orden de movimiento donde existe un automovimiento en el cual se reproduce y conserva el mismo orden, en un proceso constante. Si se quiere entender esto, pueden no bastar las fábulas-relato ingeniosas del Timeo las cuales narran al mundo como una obra divina. Es necesario elevar el ser natural del mundo como concepto. Para ello, Aristóteles sigue todavía, como [209] el Sócrates platónico, el patrón de la naturalidad del artesano que entiende su arte. Pero él gana desde ahí, el conjunto de los conceptos que abarcan de qué manera la naturaleza se piensa. A esto pertenecen tanto la hyle como el impulso del movimiento que existe dondequiera que esté la naturaleza. La naturaleza justamente no representa, tan sólo, el aspecto del orden ideal de la ejemplaridad y de la perfección como la piensa la inteligencia matemática: el ejemplo de la techne tiene la determinación de pensar la naturaleza desde las posibilidades de la propia naturalidad.

Esto no significa un antropomorfismo dogmático, sino un modo de plantear un problema que abarque todo. "Entender de una manera humana" a la naturaleza quiere también decir, que se quiere, por lo menos, entender al hombre muy naturalmente como un ser natural y como un ente que, en medio de la naturaleza, lleva una vida tal que se basa, contrario a todos los restantes seres vivos, en elegir y preferir, y así se organiza en la totalidad del mundo y en la convivencia de los hombres. Esto incluye, ciertamente, que el mundo es de tal modo que uno puede organizarse en él, eligiendo o comportándose de una o de otra manera. La techne como también la praxis social del hombre tan sólo son posibles porque en esta naturaleza no todo transcurre reservado fijamente a un fin especial, sino porque la naturaleza deja abiertos espacios de indeterminación y discreción. Hasta aquí la naturalidad del hombre está aunada al aspecto que el mundo le ofrece. Le permite formar sus propios horizontes de propósitos limitados, pero con posibilidades abiertas de formación y estructuración. Para que el hombre tenga la hyle, a saber, la materia para lograr su trabajo de formación humano debe existir "la hyle". Es una tesis casi tautológica: para que sea posible la formación debe existir la posibilidad para ello. Exclusivamente desde la ontología de la dynamis y la energeia, es posible pensar, de una manera adecuada, los conceptos descriptivos de las cuatro causas. En esta totalidad de la autocomprensión y de la comprensión del mundo por el hombre debe encontrar su lugar lo que se puede denominar, en su más alto sentido, cognición. Esto se encuentra en el sentido del derecho al ideal teórico de la vida como tal -y de esto, no en último lugar, forma parte el hecho de que se piense la naturaleza como naturaleza, a saber, como el ámbito del ser, donde nada, como en la praxis humana, se origina a través de una 
decisión de elegir, la selección de los medios oportunos, o de la selección de los materiales adecuados etcétera, sino, por el contrario, todo sigue su curso normal, "por sí mismo"-.

Éste, ciertamente, es el ser de la naturaleza y así se le presenta al hombre. Pero por esto justamente preguntan tanto Platón como Aristóteles. Se pueden entender sus respuestas tan sólo si se entiende su pregunta. En efecto, es correcto, que Sócrates no encuentra lo que él podría "entender" del empirismo de los investigadores de la naturaleza, pero de ninguna manera es correcto que con ello se ponga en tela de juicio el empirismo infinito como tal de los investigadores de la naturaleza. Aristóteles mismo da, en un sinnúmero de ámbitos, ejemplos de su participación ferviente en el empirismo infini[210] to (compárense también, entre otros, sus ejemplos astronómicos y biológicos en Met. H 4). Los grandes adelantos de la ciencia helenística, sobre todo, en las áreas de la astronomía, la mecánica y la medicina y, en general, la emancipación de las ciencias particulares en la época helenística, son un testimonio indirecto de ello. La conocida ironía de Sócrates que describe cómo su seguimiento a los estudios sobre la naturaleza de su época lo deja más ignorante que antes, debe entenderse en su plena ambigüedad. Ella no desestima -sino alude a una omisión-. Éste es el malentendido grave de la teleología platónico-aristotélica que dice que las "causas finales" explican los procesos de la naturaleza de la misma manera como lo hacen las causas movientes. Esto es ya, de por sí, un disparate porque, la única manera como las "causas finales", a saber, las finalidades (telos), pueden surtir efecto, es precisamente, como nos lo enseña el ejemplo de la techne, vía una causa eficiente: en el caso de la techne consiste en que una persona que domina la techne ponga manos a la obra con vistas al telos -en el caso de la naturaleza, en cuanto en ella exista el nacer y el perecer, que exista un ser de un determinado género que sea capaz de procrear-. Después de todo, Aristóteles fue el hijo de un médico y, como es sabido, conoció bastante de embriología. Por supuesto, él también tuvo presente que la analogía con el entendimiento técnico del ser del cual concebía su intelección, también incluía la posibilidad de malformaciones erróneas. Pero la palabra malformación todavía a nosotros nos dice que está ideada a partir de una norma. Aristóteles hace valer expresamente, en contra de la teoría empedóclea acerca de la mezcla de los miembros ya acabados del cuerpo que, tales malformaciones provienen, desde un inicio nocivo, el semen. ${ }^{8}$ Él sabe lo que es la "naturaleza". Así, su propia teoría de las cuatro causas, sirve precisamente para la meta de unir el aspecto teleológico-eidético con el aspecto hylético. Esto significa que él puede atribuir a la hyle todos los procesos naturales que contravienen lo que se espera de las reglas. Pero, ¿qué significa esto? Ciertamente no, que en

\footnotetext{
${ }^{8}$ Aristóteles, De Part. Anim. A1, 640a 19 ss. y 641b 29.
} 
este caso "actuara" un principio. Incluso la generatio aequivoca que supone Aristóteles expresa que una determinada acción combinada de calor y humedad es lo que crea la vida -y no "la materia"-.

Así, Aristóteles ve la naturaleza, tanto desde el orden como desde la regularidad, de forma que la excepción, a saber, todo lo contrario a la regla, se deja al margen, como casual ( $\kappa \alpha \tau \alpha$ $\sigma v \mu \beta \varepsilon \beta \eta \kappa o ́ \varsigma)$. Justo esto, es la razón por la cual Aristóteles obtiene el concepto de la hyle y su función a través de la exacta extrapolación de la función del material, en el área de la techne. Al igual que el artesano, que hace la pieza de arte, se interesa solamente por su material en la medida en que éste sea idóneo -lo que tal vez presupone la producción de tal material y esto significa, a su vez, un proceder artesanal-así [211] también nosotros entendemos el orden funcional regulado de la naturaleza de tal manera que siempre incluye la hyle -pero sólo relativo a lo que necesariamente debe estar ahí-. La analogía de la physis y la techne nos enseña aún más. Quién, como los antiguos, trató de pensar el ser de la naturaleza, exclusivamente, "a

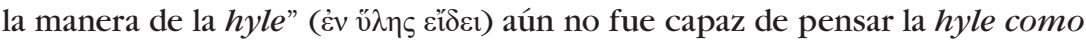
hyle, porque todavía no concibió el carácter del eidos que forma parte del ser de la naturaleza. Ésta es la clara lección de la crítica que Aristóteles ejercita sobre los filósofos antiguos. Hay, tan sólo, hyle, porque la naturaleza es algo más que pura presencia.

En qué sentido el telos circunscribe el horizonte conceptual del pensamiento de la naturaleza y el hecho de que Aristóteles llevó el segundo mejor camino, el refugio en los discursos, hasta el cabal desarrollo conceptual de lo que es la naturaleza, ahora se torna también indirectamente manifiesto. Es que se puede observar de qué manera Aristóteles, no solamente aproxima sus propias ideas al pensamiento de los antiguos, sino también reestructura, a su vez, las ideas de estos antiguos cuya labor de investigación, como tal, también para él fue fundamental. Son, sobre todo, las expresiones del "por sí mismo" y

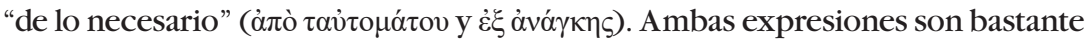
usuales, pero se tornan, si no me equivoco del todo, en conceptos ilustrativos que corresponden a la cosmología y física de los antiguos, en particular a los teóricos corpusculares. Lo que no tiene una causa específica o una causa intencional en lo relativo a la techne, eso se da por sí mismo -o también: para lo que no requiere un fundamento especial, eso acontece necesariamente-. Como sea que se acentúe la manera de expresarse a través de la cual los antiguos estudiosos de la naturaleza, particularmente los de Abdera, formularon, por lo visto, su crítica a toda la mitología -en el momento en el cual uno la eleva en su contenido conceptual a la conciencia conceptual, se manifiesta la relación dialéctica con su contrario como momento significativo fundamental. Sólo desde el pensar de lo deliberado, del entorno de qué, obtiene el "por sí mismo", como también "lo necesario", su sentido preciso. 
Justo eso es lo que Aristóteles muestra. Lo casual sólo tiene sentido en el horizonte significativo de la finalidad. Con toda intención, Aristóteles sitúa lo

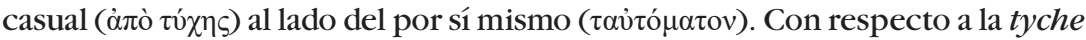
fue claro que ningún griego pasó por alto la implicación de lo "deseado" con lo "conveniente". De esa manera, Aristóteles logra convencernos de que también

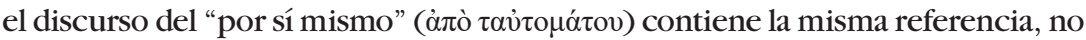
obstante, de manera subrepticia. Él muestra, por lo tanto, que también el "por sí mismo" significa una clase de casualidad, y esto quiere decir: que sólo del horizonte conceptual teleológico de la comprensión recibe su sentido. Ambas

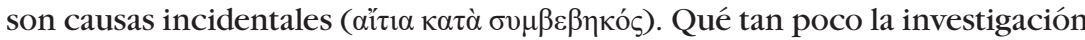
sobre las causas, en el sentido de la etiología democrítea, está en contradicción con esta dialéctica de la casualidad y el propósito intencional, nos lo enseña la alusión a la parábola del calvo: un águila deja caer [212] sobre él una tortuga porque lo toma por un peña (Fís. B6, 197b 30): mala suerte, sin duda - ¿una casualidad?-. En efecto, pero seguramente no sin razón. Así Aristóteles está muy cierto de que la casualidad no tiene que ver con el indeterminismo. "Pues mucho de lo que sucede y existe realmente por casualidad y por sí mismo, de lo cual sabemos muy bien que cada una de estas cosas se puede atribuir a determinada causalidad" (Fís. 196a 13).

En primera instancia, es menos evidente que también lo necesario tiene su lugar en la necesidad en un horizonte de referencia teleológico tal. Pero precisamente esto tiene para la formación conceptual aristotélica un significado definitivo. Él parte del hecho de que a uno, en general, algo le parece necesario para algo, quiere decir: "lo necesario" es siempre "necesario bajo una condición previa”. La necesidad hipotética se define precisamente por el hecho de que algo se manifiesta, desde un telos supuesto y, por lo tanto, como "relativamente" necesario. En este sentido también la hyle es, en el proceso técnico, una necesidad relativa tal. El material debe necesariamente estar ahí. Sin aquél no funciona nada (oṽ ov̉к ơvev). Es una concausa necesaria

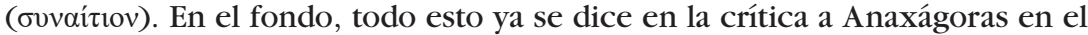
Fedón (99a-c). ¿Pero no habrá tal vez también lo absolutamente necesario ( $\tau$ ò $\dot{\alpha} \pi \lambda \tilde{\omega} \varsigma$ $\alpha v \alpha \gamma \kappa \alpha i ̃ o v)$ ? Con todo, se habla, en ocasiones, de esto en Aristóteles. Así, sobre todo, en la introducción a sus lecciones de biología (De part. an. A 1). La necesidad absoluta no es relativa a un telos determinado. ¿Hay algo semejante? Ya la formulación espontánea al correr de la pluma "no relativa a un telos determinado", contiene la respuesta. Donde no se puede explicar por qué acontece esto y no aquello, porque siempre acontece lo mismo, es "siempre ya necesario", a saber, no requiere ninguna observación adicional determinativa -como la trayectoria de los astros donde no existe ningún poderser-diferente. Hasta aquí existe lo absolutamente necesario como aquello que no puede ser diferente. En su juventud, Aristóteles parece haber atribuido 
también a los astros una especie de "elección" (prohairesis) en sus trayectorias. Si después ya no lo hizo, seguramente la razón no fue que le quisiera dar una mayor cabida a la necesidad. Por el contrario. El mantener la trayectoria exacta les hizo a los astros muy admirables y ejemplares para los griegos y, por eso, él prefiere describir, más tarde, este comportamiento desde una techne completamente dominada que hacerlo desde la práctica humana que requiere la deliberación y la selección circunspecta. Así lo hace él también en relación con la naturaleza en su conjunto (Fís. B8). En contraposición, en el ámbito de lo que nace y perece todo es siempre relativamente necesario, a saber, necesario para lo que nace y perece. Este "qué" es lo primero. Para que la naturaleza pueda existir en la regularidad constante de sus formas del qué, tiene que haber necesariamente, aquello que las hace posible existir. Esta necesidad, por lo tanto, forma parte del dominio de la hyle. Lo necesario "lo que suele decirse como hyle" ( $\tau$ ò $\omega \varsigma$ v̌ $\lambda \eta \lambda \varepsilon \gamma o ́ \mu \varepsilon v o v$ ).

[213] ¿Qué quiere decir realmente hyle? Siempre debemos regresar a la misma pregunta. Si se repara cuán amplio sentido abarca Aristóteles cuando habla acerca del "de qué"9 y en cuántos ámbitos él usa la expresión hyle, uno se ve en la necesidad de desligar la función conceptual de la hyle como tal de todas sus "manifestaciones". Aristóteles mismo distingue, ocasionalmente, la hyle sensorial de la hyle intelectual; y es menester hablar también de una hyle tópica: especialmente la investigación moderna sobre la academia platónica lo concretó (Happ). El material manifiesto que todavía no es la pieza labrada, carne y huesos que como tales aún no son el ser viviente, el género universal que todavía no representa, a través de una diferenciación específica, el ser qué de algo, la extensión espacial que todavía no es la figura geométrica formada por líneas -todo esto es denominado hyle por Aristóteles-. La hyle siempre se refiere, análogamente, a la forma, como lo posible a lo real, como la determinación posible a la determinación misma. Sin duda son diferentes las maneras de coincidencia en las cuales se presenta este margen de incertitud. El artesano ve en el material la posible pieza labrada. Quien quiere concebir un ser natural en su esencia tal vez ve en el casi adulto su futura madurez, o la futura articulación en lo aún indiferenciado, acaso en el embrión. Por otro lado, él también ve como algo lógico, la indeterminación de lo que aún está indiferenciado, a saber, él ve en lo universal, todavía no definido, el aún-no de la determinación de la esencia plena. En el caso del uso matemático extensivo de la hyle los dos aspectos se van al unísono, indistinguiblemente. Pues, ¿qué será aquí la construcción y qué la definición? La esencia del triángulo reside en todos los triángulos. Todo triángulo es la suma angular de dos rectos.

${ }^{9}$ N. T.: Gadamer se refiere a la causa material aristotélica, es decir, "de qué" está hecho algo. 
Para lo que nosotros aquí denominamos siempre el "aún no" o lo "posible", Aristóteles usa la expresión conceptual de las dynamei, que siempre hacen referencia a una energeia. Lo que las dynamei son, tiene siempre el carácter de lo indefinido-universal que se refiere a la certeza que aún no la tiene. Por lo tanto, se debe plantear en serio la pregunta de si lo indeterminado, en el sentido lógico, y los posibles, en el sentido de la hyle, no forman un conjunto indisoluble, porque ambos tienen el ser exclusivamente en el "qué" determinado. Aristóteles realiza, bajo el lema de la unidad de la definición, esta identidad de significado principal de lo posible e indeterminado con el "qué" de lo determinado, en la Metafísica $\mathrm{H}$ y logra así elaborar un sentido conceptual común de la hyle. Esto, sin embargo, significaría que aquí no tenemos que ver con "tipos" de hyle a los cuales también pertenece el caso lógico del género (genos), sino a la inversa, que en todos los casos, el sentido lógico, universal de hyle es aquel de la indeterminación, pero eso quiere decir la universalidad del género.

[214] Aristóteles no estableció su discurso sobre la hyle exclusivamente en el contexto de la teoría de la definición y, por lo tanto, la hyle muchas veces tiene una aplicación que sugiere el sentido incorrecto de que se trata de algo que existe por sí sólo. La connotación de "madera en bruto", la madera para carpintería que resuena en la expresión conceptual hyle, establece unívocamente el sentido conceptual de hyle, en el contexto sistemático de las cuatro causas y las explicación detallada que encontramos en el " $\mathrm{H}$ " de la Metafísica muestran la estructura meramente análoga de este concepto. Esto no es un funcionalismo moderno que se pudiera criticar desde el trasfondo de las diferentes aplicaciones, no implícitas al concepto de hyle sino, por el contrario, es el efecto expreso del análisis conceptual aristotélico. Hyle no es la materia última, la más abstracta, la más lejana, una materia básica de la cual deviene todo. Donde Aristóteles habla así, él está describiendo un pensamiento más antiguo que no reparó en ello (1044a 15 ss). El sentido de hyle se cumple más bien por el hecho de que en el ser de lo existente se encuentra algo que se escapa de la palabra determinante, del saber, de la presencia plena de su ser verdadero y de su ser-qué. La hyle es siempre "tan sólo" hyle, un resto de indeterminación y discrecionalidad que se presenta como una carencia de ser. Lo existente que no tiene hyle es lo puro existente (energeia pura). Incluso los eternos astros tienen un resto de indeterminación y, por lo tanto, hyle, a saber: el "aún no" imprescindible de su movimiento giratorio. Su "lugar" es lógicamente separable de su ser, así como el material es lógicamente separable de lo "que" algo es, ya que, en efecto, puede ser también fabricado en otro material.

Por supuesto, el modo aristotélico de plantear un problema está enfocado, de primera intención y más que nada, al ser de lo existente por naturaleza. Ahí, en efecto, por lo menos en el ámbito del devenir y del desvanecerse, la 
hyle no es visible separada de la esencia misma, sino que aquella está siempre

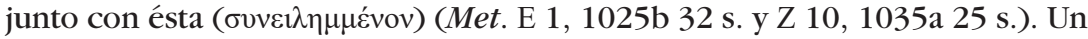
hombre siempre está hecho de carne y sangre, una columna no siempre de bronce. No obstante, también aquí existe una separación en el pensamiento ( $\tau$ ñ $\delta$ ¿voía). No todo lo que está hecho de carne y sangre, es un hombre. Si uno se pregunta por lo que integra su ser en tal existente, la carne y la sangre mismas pueden ser vistas, tan sólo, como lo universal del género. Se puede separar del hombre concreto y de su ser hombre. Se nombrará también un cadáver: ya no es más "él". Pues que "él" lo es, quiere decir, que es este hombre preciso. Por lo tanto, la materia no es, de ninguna manera "el principio de la individuación". Más bien, ella pudiera llamarse el principio de la no-individuación. Pues ella es "nada más hyle", por decirlo así, la madera en bruto para todo ser-qué y ser-cognoscible, discrecional visto desde ella, aunque también constituya su sustrato necesario ( co", para el discurso determinante siempre es lo relativamente indeterminado. En el saber del qué (definición) se define la inde[215]terminación del género a través del eidos que constituye la diferencia. En el saber de la techne se ve el eidos dentro del material dado y si al "físico" no le interesa en exclusiva -pero sí en primera instancia- el eidos, sino también la hyle, este "de qué" de lo que se compone el existente natural, sólo está en lo existente mismo:

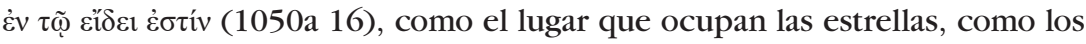
elementos en el ámbito del devenir y del perecer, como la tierra en la semilla. Es lo universal indeterminado que "aún no" es la cosa misma que está como hyle "en el logos". La hyle siempre es la hyle del logos.

Por lo tanto, me parece interesante que en los escritos de Alejandro de Afrodisias se encuentra un pequeño ensayo que trata expresamente la cuestión referente a si la hyle no será nada más que el género. ${ }^{10}$ Los argumentos en contra ahí citados donde, de una manera sorprendente, faltan alusiones a Aristóteles, abundan en vocablos de concreción al estilo del concepto de hipostásis neoplatónico: la hyle es algo real $(\pi \rho \tilde{\alpha} \gamma \mu \alpha)$, el género es una mera

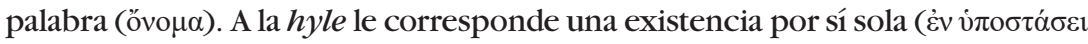

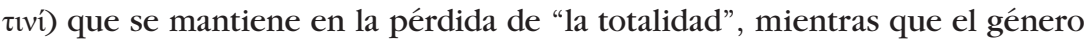

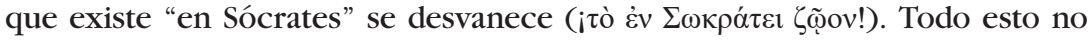
es muy interesante. Pero la pregunta interesante es aquí: ¿quién entendió a Aristóteles tan bien ya que, en este ensayo, él debiera ser refutado? Tal vez quien lo entendió correctamente.

Al final parece que Stenzel tiene razón, cuando él está en contra de introducir, en la hyle aristotélica, el significado corpóreo en el sentido de la materia palpable (Zahl und Gestalt, 131). Debemos aprender a defender la manera

${ }^{10}$ Alexandri Scripta minora, Suppl. Arist. II, 2, 77 ss. 
de pensar trascendental en contra del dogmatismo connatural de nuestro pensamiento. Como se sabe, Kant llamó trascendental a "todo conocimiento que no se ocupa ni de los objetos ni de nuestra manera de pensar los objetos, sino en tanto que esto sea posible a priori". (Crítica de la razón pura, Introducción). En este punto, Platón y Aristóteles están vinculados con él: ellos trataron de conocer, en vez de los pragmata, en los logoi, el verdadero ser de

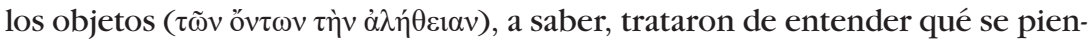
sa, desde siempre, de aquello sobre lo cual se habla. Desde una perspectiva histórica, sin embargo, Stenzel no tiene razón cuando ubica, hasta el siglo XIX la degradación del concepto de lo material a la materia palpable. Aquí Nicolai Hartmann observó, correctamente, que se debiera reconocer este desarrollo, por lo menos, desde la Estoa. ${ }^{11}$ Pero él, por su parte, no se percató del significado fundamental de su propia corrección de la perspectiva histórica. Lo que él argumenta en contra de la consecuencia asumida por Stenzel, de pensar la hyle como género [216] comprueba que él mismo no toma en serio el sentido funcional de los conceptos aristotélicos de hyle, eidos y synholon, y cede ante la concreción cuyos principios históricos él los sitúa correctamente. Lo que se hizo en los últimos ciento cincuenta años a favor de Platón falta llevarlo a cabo por Aristóteles. En el caso de Platón se trata de liberar al Platón original de su reinterpretación neoplatónica. En el caso de Aristóteles lo que importa es algo parecido, en particular desde que la investigación de un cierto movimiento retrospectivo aproxima los inicios del neoplatonismo cada vez más a Platón y Aristóteles. Esto ya no puede involucionar a Platón como dogmático, pero aún falta mucho para que se pueda considerar a Aristóteles separado del dogmatismo. ${ }^{12}$

Hegel, hasta nuestros días, tiene razón cuando dice de Aristóteles "que a ningún filósofo se le trató tan injustamente debido a las tradiciones inconsideradas que se mantuvieron a través de su filosofía y que todavía están vigentes" (XIV, 299). La liberación de las ideas inconsideradas, en especial lo que significa "el principio" y "el concepto", es un esfuerzo particular tanto en la filosofía como en las ciencias que nunca queda completamente satisfecho. En la física moderna vemos magníficos actos de liberación de este modo, y pa ra la legitimación de esta nueva actitud antidogmática de conceptos se remitió muchas veces a Kant y de ahí a Galileo y Platón. No se debiera haber pasado

${ }^{11}$ N. Hartmann, op. cit., p. 140.

${ }^{12}$ Philipp Merlan, al que justo a este respecto se le debe mucho ("From Platonism

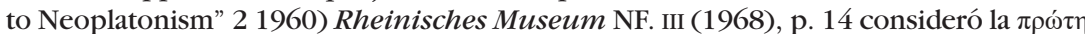
¿ $\lambda \eta$ todavía por completo como una hipostatización aristotélica $-\mathrm{y}$ como tal la refutó con argumentos convincentes-. [Revisar: http://rhm.phil-fak.uni-koeln.de/?L=1, también: http://rhm.phil-fak.uni-koeln.de/1960-1969.html, y http://www.rhm.uni-koeln. de/111/Merlan.pdf]. 
por alto a Aristóteles. Él acuñó sus conceptos constantemente con vistas a su función comprensiva y siempre transformó, de nueva cuenta, todas las palabras conceptuales en su universalidad funcional, como en aquella frase única, que

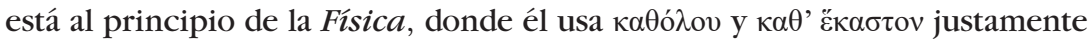
en el sentido opuesto al cual normalmente se usa (Fís. 184a 23).

El "maestro de aquellos que saben" concentró la pasión por el saber y el gusto por la investigación de los griegos en un todo de orientación mundial y la naturalidad con que dominó mil años el espíritu europeo. Si la ciencia y el gusto por la investigación del mundo moderno pudieron desplegarse solamente debido a que sacudieron su dominio intelectual, el pensamiento de Aristóteles gana para nosotros una nueva ejemplaridad, desde que empezamos a redescubrir el Aristóteles especulativo que se encuentra detrás de su dogmática figura tradicional. Él fue una persona que sabía lo que es un concepto - no un signo discrecional para una cosa conocida, sino una guí[217]a del pensamiento, el cual quiere pensar algo mediante aquello con lo cual piensa, también en lo relativo a la "materia".$-{ }^{13}$

Traducción: María Teresa Padilla Longoria Revisión: Hilde Rucker

13 [Entretanto apareció el trabajo agudo de H. J. Krämer, "Aristóteles y la teoría académica del eidos", Archiv für Geschichte der Philosophie, 1973, t. 55, pp. 119-190. El presente estudio que en realidad no contempla una diferencia esencial entre Categorías 5 y la teoría del eidos de la Metafísica, sería declarado de obsoleto por Krämer. Yo, por mi parte, creo que él subestima la flexibilidad del uso del lenguaje aristotélico -como del lenguaje filosófico verdadero en su totalidad- y que establece sus construcciones agudas sobre un fundamento demasiado movedizo.

Que también él, como Happ, habla de la forma-eidos de una manera tan hipostática, diciendo que es la causa del movimiento, a saber "un principio teleológico-dinámico", le seduce a la aseveración osada de que la forma-eidos no es кaӨódov a pesar de su universalidad -una tesis completamente incomprensible-.

A mi entender, él sigue subestimando objetivamente -lo que muestra su crítica de mi página $129 \mathrm{~s}$. - el peso que tiene la Física para la "fundamentación del giro ontológico" del problema de las categorías.] 